\title{
Effect of discharge and upstream jam angle on the flow distribution beneath a simulated ice jam
}

\author{
Baafour Nyantekyi-Kwakye, Tanzim Ahmed, Shawn P. Clark, Mark F. Tachie, and Karen Dow
}

\begin{abstract}
The velocity field beneath simulated rough ice jams under various upstream jam angles and discharge were investigated using a particle image velocimetry system. Three discharges were examined at $2.3 \mathrm{~L} / \mathrm{s}, 3.4 \mathrm{~L} / \mathrm{s}$, and $4.0 \mathrm{~L} / \mathrm{s}$ and two upstream ice jam angles were tested at $4^{\circ}$ and $6^{\circ}$. Increasing the discharge resulted in high turbulence production beneath the jam. The adverse pressure gradient exerted on the flow increased the levels of the Reynolds shear stress. The measured velocities beneath the jam were used to assess the performances of three traditional field measurement techniques as well as the validity of the two-parameter power law. The two-point measurement technique performed remarkably well with the least mean bias error of $2.0 \%$. The error associated with the different techniques showed their inability to accurately predict the average velocity under high discharge. The two-parameter power law accurately predicted velocity profiles within the equilibrium section of the jam, but failed within the boundary layers when the flow was subjected to a pressure gradient.
\end{abstract}

Key words: discharge, ice jam, Reynolds shear stress, river ice, rough surface, turbulent kinetic energy.

Résumé : Le champ de vitesse sous les embâcles simulés selon divers angles de blocage et différents débits en amont d'un cours d'eau a été étudié à l'aide d'un système de vélocimétrie par images de particules. Trois débits d'eau ont été examinés, soit 2,3, 3,4 et $4,0 \mathrm{~L} / \mathrm{s}$, et deux angles d'embâcle en amont ont été mis à l'essai, soit $4^{\circ}$ et $6^{\circ}$. L'augmentation du débit a entraîné une forte production de turbulence sous l'embâcle. Le gradient de pression nuisible exercé sur l'écoulement a causé une augmentation des niveaux de la tension de Reynolds. Les vitesses mesurées sous l'embâcle ont été utilisées pour évaluer les rendements de trois techniques traditionnelles de mesure sur le terrain ainsi que la validité de la loi de puissance à deux paramètres. La technique de mesure en deux points a donné d'excellents résultats, avec la moindre erreur de justesse moyenne de $2,0 \%$. L'erreur associée aux différentes techniques a indiqué l'incapacité de celles-ci à prédire avec précision la vitesse moyenne en cas de débit d'eau élevé. La loi de puissance à deux paramètres a prédit avec précision les profils de vitesse dans la région d'équilibre de l'embâcle, mais elle s'est failli pour les couches limites lorsque l'écoulement a été soumis à un gradient de pression. [Traduit par la Rédaction]

Mots-clés : débit d'eau, embâcle, tension de Reynolds, glace fluviale, surface rugueuse, énergie cinétique turbulente.

\section{Introduction}

Many of the rivers in Canada freeze during the winter season. The formation of an ice cover affects streamflow gauging stations across the country. Current procedures used to determine discharge beneath ice covers rely heavily on approximations due to frigid winter weather conditions as well as safety concerns. However, several studies have used these methods to approximate mean velocities, and subsequent discharge values under ice conditions. Although some flow measurements have been reported beneath intact ice covers, the same cannot be said for ice jams. This is due to the unstable nature of jams, which poses major safety concerns. There is therefore a lack of accurate data for thoroughly investigating the flow beneath ice jams.

Figure 1 shows a schematic of an equilibrium ice jam consisting of the upstream transition, equilibrium region, and downstream transition. The upstream transition is characterized by a gradual increase in the jam thickness until it reaches a uniform value within the equilibrium region. The slope of the water surface remains constant in the equilibrium region. The jam thickness increases steeply, and the slope of the water surface becomes steeper than the bed slope as the toe is approached in the downstream transition. The downstream transition consists of two sections: the upper and lower toe sections, where the toe denotes the point of maximum ice thickness of the jam. Based on the configuration of jams, the flow beneath them is subjected to varying pressure gradients, such as favorable pressure gradient (FPG) and adverse pressure gradient (APG) within the upper and lower toe sections, respectively. The existence of different pressure gradients beneath the jam modifies the turbulent flow characteristics considerably compared to events in open water and uniformly ice-covered flows (Nyantekyi-Kwakye et al. 2018).

Different measurement techniques have been adopted in the past to detail average velocities beneath ice-covered rivers. The widely used techniques by the Water Survey of Canada include: (1) complete wall-normal velocity curve, (2) two-point technique, (3) three-point technique, and (4) six-tenths depth. In the first technique, pointwise velocity measurements are conducted at increments of $0.1 h$ (where $h$ is the flow depth). From the pointwise measurements, the average velocity is estimated by integrating the velocity curve and dividing the resulting value by the flow depth, $h$. This approach is time consuming and as such rarely

Received 21 March 2018. Accepted 20 October 2018.

B. Nyantekyi-Kwakye. Department of Mechanical Engineering, Memorial University of Newfoundland, St. John's, NL, Canada.

T. Ahmed, S.P. Clark, and K. Dow. Department of Civil Engineering, University of Manitoba, Winnipeg, MB, Canada.

M.F. Tachie. Department of Mechanical Engineering, University of Manitoba, Winnipeg, MB, Canada.

Corresponding author: Baafour Nyantekyi-Kwakye (email: bnyantekyikw@mun.ca).

Copyright remains with the author(s) or their institution(s). Permission for reuse (free in most cases) can be obtained from RightsLink. 
Fig. 1. Schematic of an equilibrium ice jam (reprinted from Beltaos 2001 with permission from ASCE). [Colour online.]

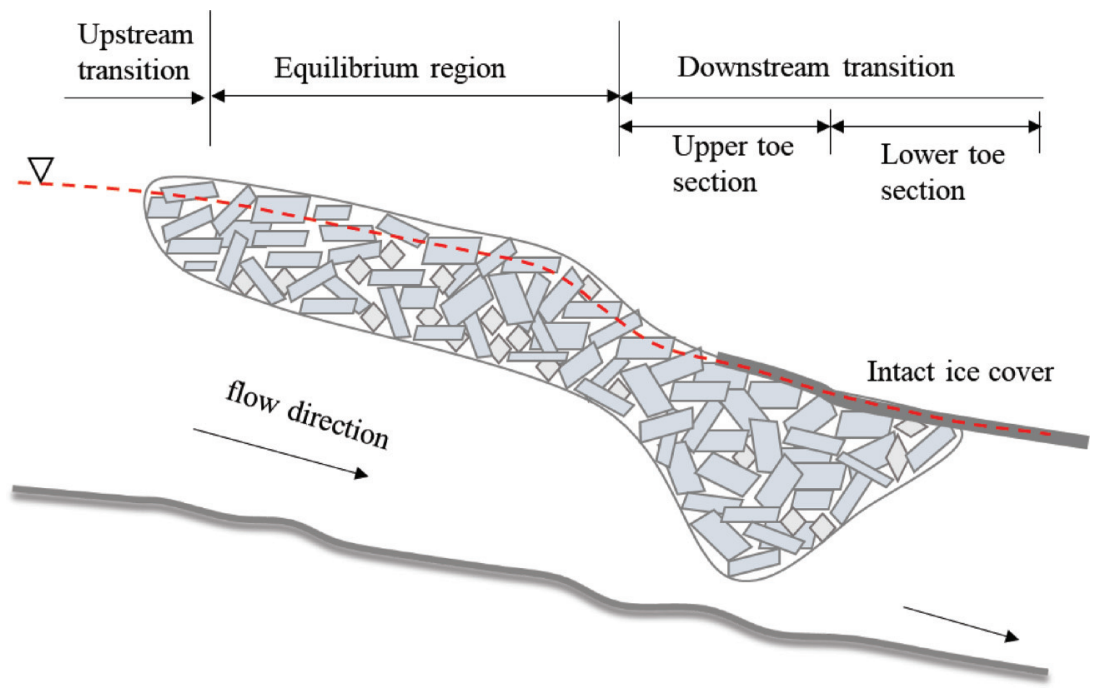

adopted in winter for velocity measurements. With the two-point method, velocity measurements are taken at $0.2 \mathrm{~h}$ and $0.8 \mathrm{~h}$, and then averaged to obtain the mean velocity. For the three-point technique, velocity measurements are conducted at $0.2 h, 0.6 h$, and $0.8 \mathrm{~h}$ and then averaged. Lastly, in the six-tenths depth approach, velocity measurement is conducted at $0.6 \mathrm{~h}$ and the mean velocity estimated by multiplying the measured velocity by a coefficient of 0.92. The reason for the coefficient is to account for the non-uniformity of the mean velocity profile because of the ice cover (Teal et al. 1994). The coefficients have been observed to vary considerably at different measurement stations (Walker and Wang 1997). Teal et al. (1994) studied these techniques and observed that the six-tenth measurement yielded much more accurate results for shallow streams compared with the other methods. However, the two-point, three-point, and the sixth-tenth methods all failed to yield accurate results for flows over a wide range of roughness.

Healy et al. (2002) measured unsteady flow velocity (with discharge ranging from $40 \mathrm{~L} / \mathrm{s}$ to $65 \mathrm{~L} / \mathrm{s}$ ) beneath a simulated floating ice cover using Prandtl tubes (PT) and an acoustic Doppler velocimeter (ADV). The average velocity obtained from the two measurements was compared to that estimated using the two-point method. The estimated average velocity using the two-point method agreed with that obtained from both the PT and ADV measurements; suggesting the applicability of the two-point method in unsteady flow conditions.

To date, most of the velocity measurements reported in the literature are for steady, uniformly ice-covered flows. Not much has been done beneath ice jams due to their unsteady and nonuniform nature. The only studies that have dealt with velocity measurement beneath simulated ice jams have been reported by Pahlavan et al. (2015, 2016) using an ADV. The authors observed wide variations in the mean flow and turbulence fields when boundary roughness was altered. In recent times, particle image velocimetry (PIV) has gained prominence for conducting velocity measurements under simulated ice-covered flows due to its ability to map the spatial flow field. The present authors have conducted detailed PIV measurements to investigate turbulent structures beneath a simulated ice jam and reported the findings in Nyantekyi-Kwakye et al. (2018). Based on the previous findings, the objective of the present experiment was to quantify the flow characteristics beneath a simulated rough ice jam using a highresolution PIV for different discharges as well as upstream jam angles; and also assess the performance of traditional field measurement techniques (two-point, three-point, six-tenths depth).

\section{Theoretical background}

The formation of ice cover on rivers increases flow resistance and flow depth. The imposition of this additional solid boundary increases the wetted perimeter and changes the flow characteristics. Figure 2 shows a typical streamwise mean velocity profile beneath an ice cover. The formation of two distinct boundary layers (for the bed and ice cover) alters the velocity profile under ice-covered conditions. The presence of roughness on the bed and (or) ice cover will further alter the velocity distribution, with the maximum velocity shifting away from the rougher of the two boundaries. It is therefore necessary to assess the ability of the field techniques in the presence of an asymmetric roughness distribution. It is also inappropriate to extend velocity approximations developed for open water flow to ice-covered flow, since they cannot describe the entire velocity profile. Teal et al. (1994) adopted a two-parameter power law expressed in eq. (1) to describe the entire velocity profile beneath an ice-covered flow.

(1) $\quad U=K_{0}\left(\frac{y}{h}\right)^{1 / m_{\mathrm{b}}}\left(1-\frac{y}{h}\right)^{1 / m_{\mathrm{i}}}$

where $K_{0}$ is a constant for a specific flow rate; $m_{\mathrm{b}}$ and $m_{\mathrm{i}}$ are parameters related to bed and ice cover (the $m$ parameters are inverse roughness coefficients), respectively. The value of $m$ is dependent on the effective roughness of the boundary under consideration. Larger values of $m$ indicate less flow resistance, whereas a lower $m$ value indicates higher flow resistance. As $m_{\mathbf{i}}$ approaches infinity, eq. (1) takes the form of a normal power law for open water flow, and $K_{0}$ becomes the maximum velocity. Teal et al. (1994) compared velocity results obtained from different point velocity measurements, and an extended two-power law to those measured on the field and laboratory. The advantage of the extended two-power law was its ability to describe the entire flow with a single continuous curve.

\section{Experimental setup}

Two experiments were conducted in a $2.5 \mathrm{~m}$ long recirculating open water channel with a square cross-section of $200 \mathrm{~mm} \times$ $200 \mathrm{~mm}$. To facilitate optical access, both sidewalls and bottom were made from smooth acrylic. A modeled ice jam fabricated from a $9 \mathrm{~mm}$ thick acrylic sheet was inserted into the flume. The height at inlet, $h$, and outlet of the modeled jam were $100 \mathrm{~mm}$ and $84 \mathrm{~mm}$, respectively as indicated in Fig. $3 a$. This design was chosen to have higher water level at the upstream compared to the down- 
Fig. 2. Typical streamwise mean velocity profile beneath an ice-covered flow ( $h$ is the flow depth). [Colour online.]

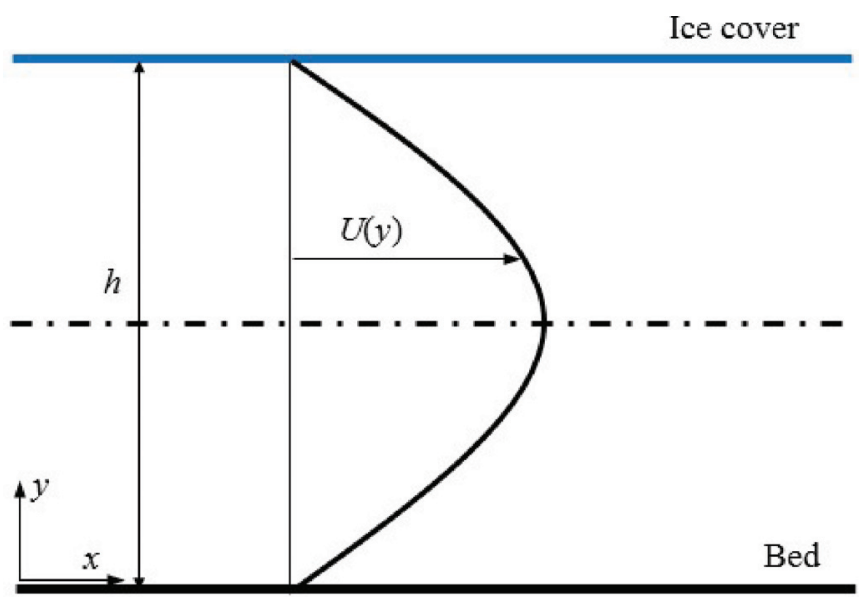

stream part of the jam to mimic the backwater effects caused by an actual ice jam. Based on the dimensions, the cross-sectional area at the inlet and outlet of the modeled jam were $0.0198 \mathrm{~m}^{2}$ and $0.0166 \mathrm{~m}^{2}$, respectively. The length of the initial section, which corresponds to the equilibrium region of the ice jam was $1000 \mathrm{~mm}$ to allow for the development of the flow before entering the upper toe section (converging section) of the jam. The flow was tripped (on the bed) at the inlet of the equilibrium region with 24-grit sandpaper (50 $\mathrm{mm}$ long and spanning the entire width of the channel) to facilitate boundary layer development. In the first experiment, $\alpha$ was maintained at $9^{\circ}$ and $\beta$ varied from $4^{\circ}$ to $6^{\circ}$ to investigate the effect of upstream angle on the mean flow at a constant discharge of $3.4 \mathrm{~L} / \mathrm{s}$. For the second experiment, the angles, $\alpha$ and $\beta$ were maintained at $9^{\circ}$ and $6^{\circ}$, respectively, while varying the discharge. The toe of the jam was fixed $36 \mathrm{~mm}$ from the bottom of the channel. The cross-sectional area at the toe of the jam was $0.0071 \mathrm{~m}^{2}$, which represents a $64 \%$ reduction in crosssectional area from the inlet. A 24-grit sand paper (with roughness height of approximately $1.8 \mathrm{~mm}$ ) was used on the channel bottom to simulate riverbed roughness. An array of acrylic cubes of height $12.7 \mathrm{~mm}$ were used as roughness elements on the ice cover to approximate the extreme roughness of ice jams observed in the field. Three different discharges were investigated at 2.3, 3.4, and $4.0 \mathrm{~L} / \mathrm{s}$, denoted herein as Q23, Q34, and Q40, respectively. The approach Froude number based on hydraulic diameter and approach bulk velocity, $U_{\mathrm{b}}$, were $0.11,0.16$, and 0.19 for $Q 23, Q 34$, and Q40, respectively.

A planar particle image velocimetry system was used to conduct the velocity measurements. The flow was seeded with $10 \mu \mathrm{m}$ silver coated hollow glass spheres with specific gravity of 1.4. The maximum settling velocity and response time of the seeding particles were estimated to be $6.25 \times 10^{-7} \mathrm{~m} / \mathrm{s}$ and $6.38 \times 10^{-8} \mathrm{~s}$, respectively. These values suggest that the seeding particles used in the present studies followed the flow. A New Wave Solo Nd:YAG doublepulsed laser with maximum energy of $120 \mathrm{~mJ}$ per pulse at $532 \mathrm{~nm}$ wavelength was used to illuminate the flow field. The laser sheet was aligned with the mid-span of the test section for measurements in the symmetry plane. To ensure reduction in lost correlation, the time interval between the laser pulses was chosen such that the maximum particle displacement was smaller than $25 \%$ of the interrogation area size. Scattered light from the tracer particles was captured with a 12-bit charge-coupled device (CCD) camera that has a resolution of 2048 pixel $\times 2048$ pixel, and a pixel pitch of $7.4 \mu \mathrm{m}$. Dantec Dynamics commercial software (DynamicStudio version 4.1) was used to control the data acquisition. A camera field of view of $112 \mathrm{~mm} \times 112 \mathrm{~mm}$ was used. Measurements were acquired in seven planes (indicated in Fig. $3 b$ by P1 to P7), with the first plane capturing the fully developed flow within the equilibrium section of the jam. Based on a convergence test, the mean velocities and turbulence statistics were calculated using 6000 instantaneous image pairs captured at a rate of $4 \mathrm{~Hz}$. The interrogation area size was set to 32 pixels $\times 32$ pixels with $50 \%$ overlap in both directions, which corresponds to physical dimensions of $0.875 \mathrm{~mm} \times 0.875 \mathrm{~mm}$. The instantaneous images were post-processed using the adaptive correlation option of DynamicStudio developed by Dantec Dynamics. An in-house MATLAB code was then used to calculate the mean velocities and higher order turbulence statistics. The uncertainty in the mean velocities, turbulence intensities, and Reynolds stresses at 95\% confidence level was estimated to be $\pm 2.7 \%, \pm 3.1 \%$, and $\pm 11 \%$ of the peak values, respectively.

\section{Results and discussion}

The first part of the discussion focuses on the effect of upstream jam angle on the mean flow, followed by the effect of discharge on the mean flow and turbulent fields. The second part focusses on assessing some field measurement techniques used to compute the average velocity.

\section{Effect of upstream jam angle}

This section investigates the effect of upstream jam angle on the mean velocity field while maintaining a constant discharge of $3.4 \mathrm{~L} / \mathrm{s}$. The streamwise mean velocity, $U$, profiles are illustrated in Fig. $4 a$. The profiles were extracted at $x=990,1250,1450,1920$, and $2070 \mathrm{~mm}$ for the $4^{\circ}$ upstream jam angle; while those for the $6^{\circ}$ upstream jam angle were extracted at $x=990,1250,1450,1620$, and $1808 \mathrm{~mm}$. The local maximum streamwise mean velocity, $U_{\mathrm{m}}$, was used as the velocity scale. The mean velocity profile was similar for the two configurations within the equilibrium region of the jam. The inception of the FPG produced a more uniform velocity profile thereby reducing the initial boundary layer generated within the equilibrium region. Beyond the toe region, the APG generated a less uniform mean velocity profile that collapsed completely for the two test cases, since the downstream angles were similar for both configurations.

Figure $4 b$ shows the distribution of $U_{\mathrm{m}}$ beneath the simulated jam. The streamwise distance was normalized by the toe height and $U_{\mathrm{b}}$ adopted as the velocity scale. Normalized values of $U_{\mathrm{m}}$ remained almost constant in the equilibrium region, since the approach flow was fully developed. The flow in the upper toe section was characterized by acceleration due to the inception of FPG, with the peak $U_{\mathrm{m}}$ occurring near the toe where the crosssectional area is smallest. This occurrence will greatly enhance sediment transport near the toe of the jam. Excessive sediment transport will lead to severe localized scouring at the toe location. The difference in $U_{\mathrm{m}}$ at the toe of the jam for upstream jam angles of $4^{\circ}$ and $6^{\circ}$ was not significant. The flow acceleration was investigated using the acceleration parameter, computed from equation (2).

$$
K_{\mathrm{v}}=\left(v / U_{\mathrm{m}}^{2}\right) \mathrm{d} U_{\mathrm{m}} / \mathrm{d} x
$$

The symbols $K_{\mathrm{v}}$ and $\nu$ are the acceleration or decelerating parameter and kinematic viscosity, respectively, and the velocity gradient, $\mathrm{d} U_{\mathrm{m}} / \mathrm{d} x$, determined using a linear fit to $U_{\mathrm{m}}$. For a given measurement plane, $\mathrm{d} U_{\mathrm{m}} / \mathrm{d} x$ was estimated from the determined values of $U_{\mathrm{m}}$. The value of $K_{\mathrm{v}}$ was approximately $4.5 \times 10^{-6}$ for both upstream angles. This means that there was no significant effect of the jam angle on the rate of change of $U$. Finally, $U_{\mathrm{m}}$ decreased within the lower toe section due to the APG imposed on the flow. The reduced flow velocities will result in the deposition of sediments transported from upstream sections. The continual erosion and deposition of bed load will modify the morphology of the riverbed. From the results, it is obvious that the range of $\beta\left(4^{\circ}\right.$ and $\left.6^{\circ}\right)$ 
Fig. 3. Schematic of the (a) modeled ice jam (all dimensions in millimeters; the numbers in parenthesis are corresponding dimensions for the $4^{\circ}$ upstream jam angle configuration), and (b) measurement planes (not drawn to scale; the dashed lines represent streamwise locations where corresponding data were extracted for the various flow discharge for analysis).
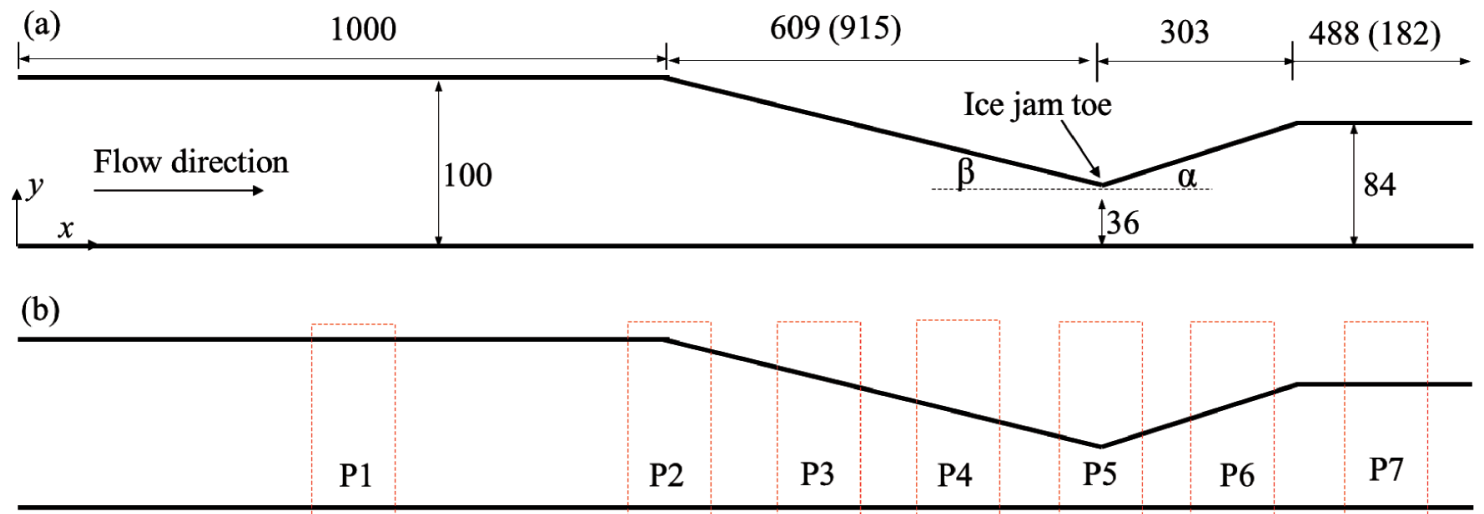

Fig. 4. (a) Profiles of streamwise mean velocity beneath a simulated ice jam with varying converging angles, and $(b)$ distribution of local maximum streamwise mean velocity. [Colour online.]
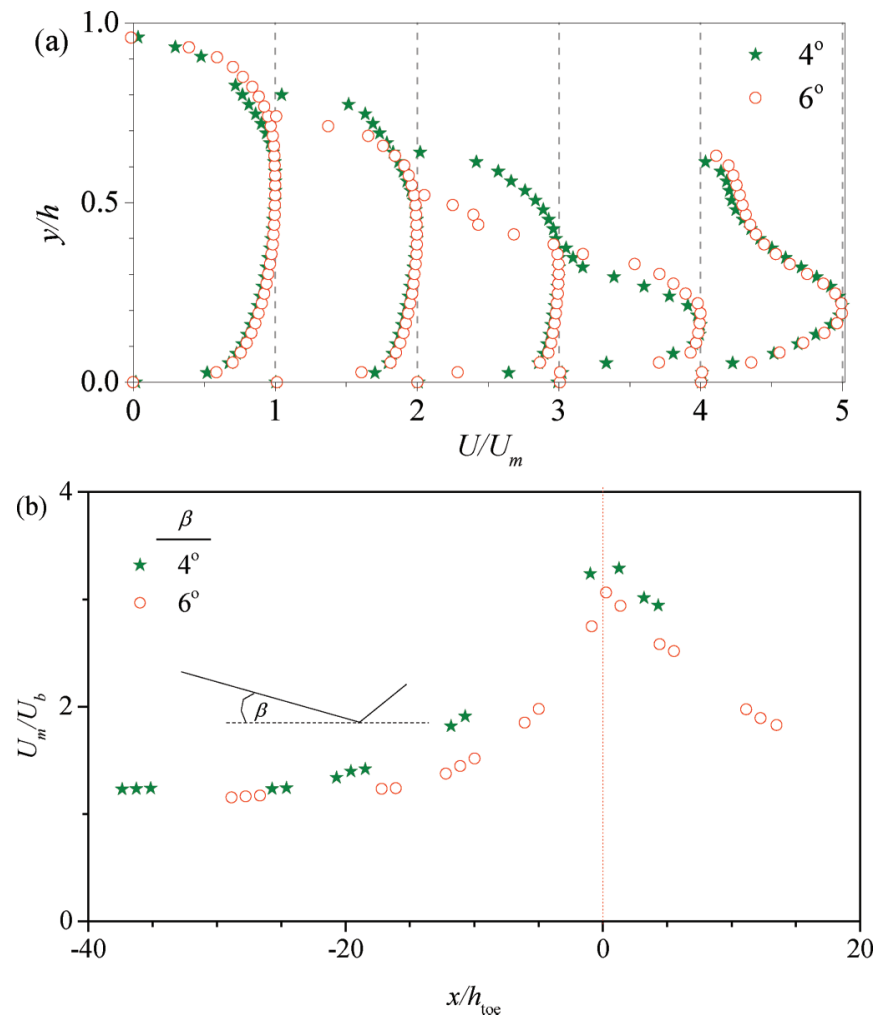

chosen was small to significantly change the dynamics of the flow, hence the discussions in the proceeding sections will focus on the effect of discharge on the flow characteristics.

\section{Effect of discharge}

\section{Mean velocity contours}

Figures 5 and 6 show contours of the streamwise and wallnormal mean velocities, respectively, within the toe and lower toe sections of the simulated jam for the different discharges. For each test case, the $U_{\mathbf{b}}$ and $h$ were selected as the velocity and length scales, respectively. Conservation of mass dictates that the flowrate is constant everywhere beneath the simulated jam. Therefore, as the toe of the jam is approached from upstream, the reduced cross-sectional area causes the mean flow to accelerate (thus $\partial U / \partial x>0)$ resulting in an FPG $(\partial P / \partial x<0)$ according to the Bernoulli principle as observed in Fig. 5. From the toe of the jam, the flow decelerates $(\partial U / \partial x<0)$ due to an increased cross-sectional area creating an APG $(\partial \mathrm{P} / \partial x<0)$. The maximum $U$ occurred at the toe section due to the drastic reduction of the flow area. The streamwise extent of the large velocity zone was not significantly affected by changing the discharge from Q23 to Q40. The normalized mean flow within the lower toe section of the jam was also not significantly influenced by changing the discharge.

The distribution of wall-normal mean velocity, $V$, is essential for investigating the possible suspension of sediments beneath the simulated jam. The direction of positive and negative $V$ are towards the ice cover and channel bottom, respectively. The normalized $V$, illustrated in Fig. 6, show regions of high negative and positive velocities beneath the ice cover within the upper and lower toe sections, respectively. This distribution persisted for the entire upper and lower toe sections where the flow was subjected to FPG and APG, respectively. Note that the decelerating flow in the presence of an APG will produce a negative $\partial U / \partial x$ but positive $V$ field, which will enhance boundary layer growth. The magnitude of normalized $V$ was greater in the upper toe section compared to the lower toe section (shown in Fig. 6), which can be attributed to the dominant role of FPG. The peak negative velocities near the ice cover of the upper toe section may have the potential to increase the likelihood of increased ice or sediment transport rates, especially considering that this coincides with the location of accelerating flow in the streamwise direction. Within the lower toe section, the mean flow decelerates, and the magnitude of $V$ reduces near the ice cover, suggesting a location where transported sediments may begin to deposit. Increasing the discharge caused a reduction in the magnitude of the normalized peak values of $V$ beneath the jam from 0.3 to 0.2 , suggesting a more likelihood of the suspended sediments settling at a faster rate at high discharge.

\section{Mean velocity profiles}

Normalized $U$ profiles beneath the simulated jam are shown in Fig. $7 a$ for selected streamwise locations. Figure $7 a$ shows an asymmetric velocity distribution at $x=970 \mathrm{~mm}$ from the inlet due to the different roughness elements used for the channel bottom and ice cover. The much rougher ice cover exerted more drag on the flow thereby resulting in a drastic reduction of $U$ close to the ice cover compared to the bottom of the channel. Within the upper toe section, where the flow was subjected to FPG, the boundary layer thickness (beneath the ice cover and channel bottom) decreased with streamwise distance. Close to the toe of the jam, the flow experienced an intense FPG, and the boundary layer tended to approach re-laminarization when compared to earlier 
Fig. 5. Contour plots of the normalized streamwise mean velocity for different flow discharge: $U^{*}=U / U_{\mathbf{b}}$. [Colour online.]
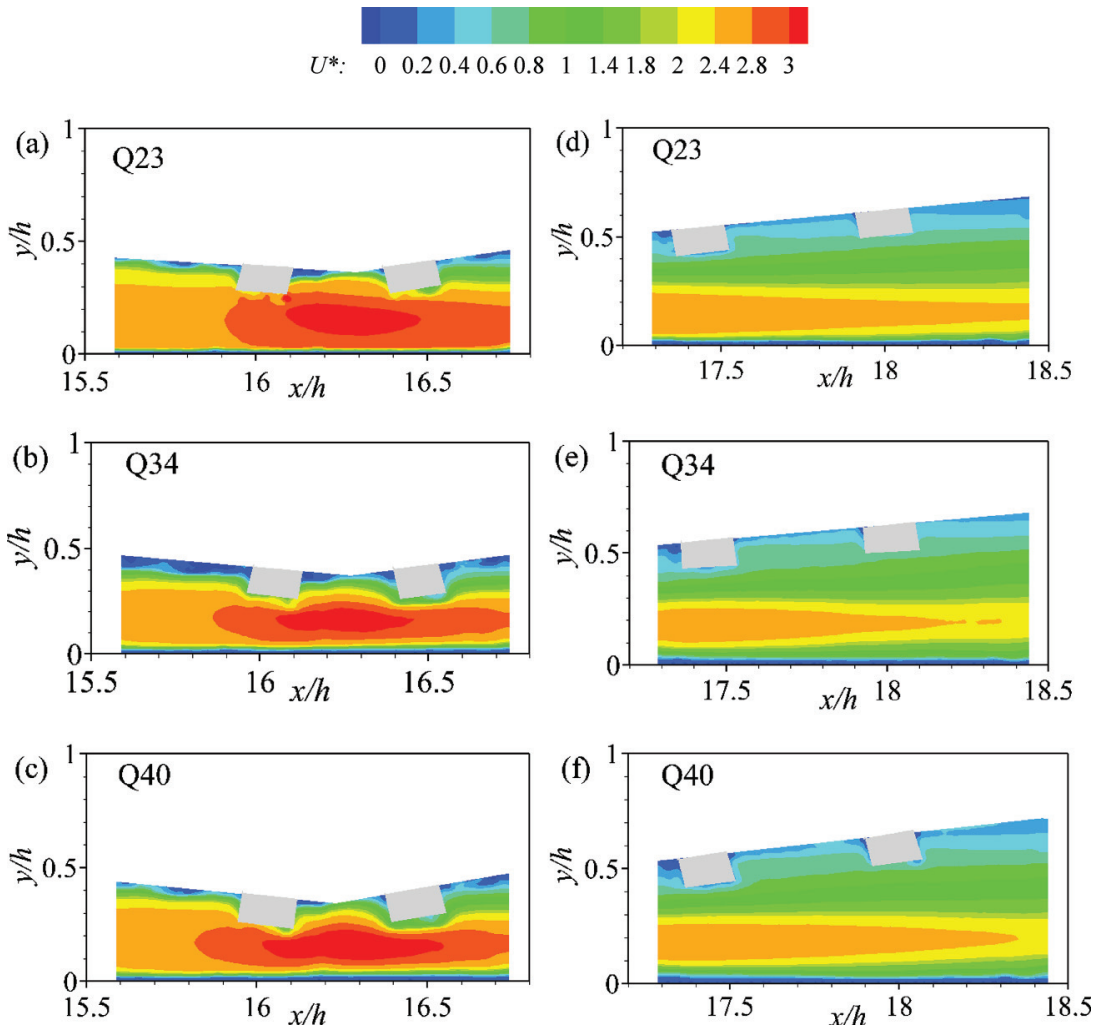

Fig. 6. Contour plots of the normalized wall-normal mean velocity for different flow discharge: $V^{*}=V / U_{\mathbf{b}}$. [Colour online.]
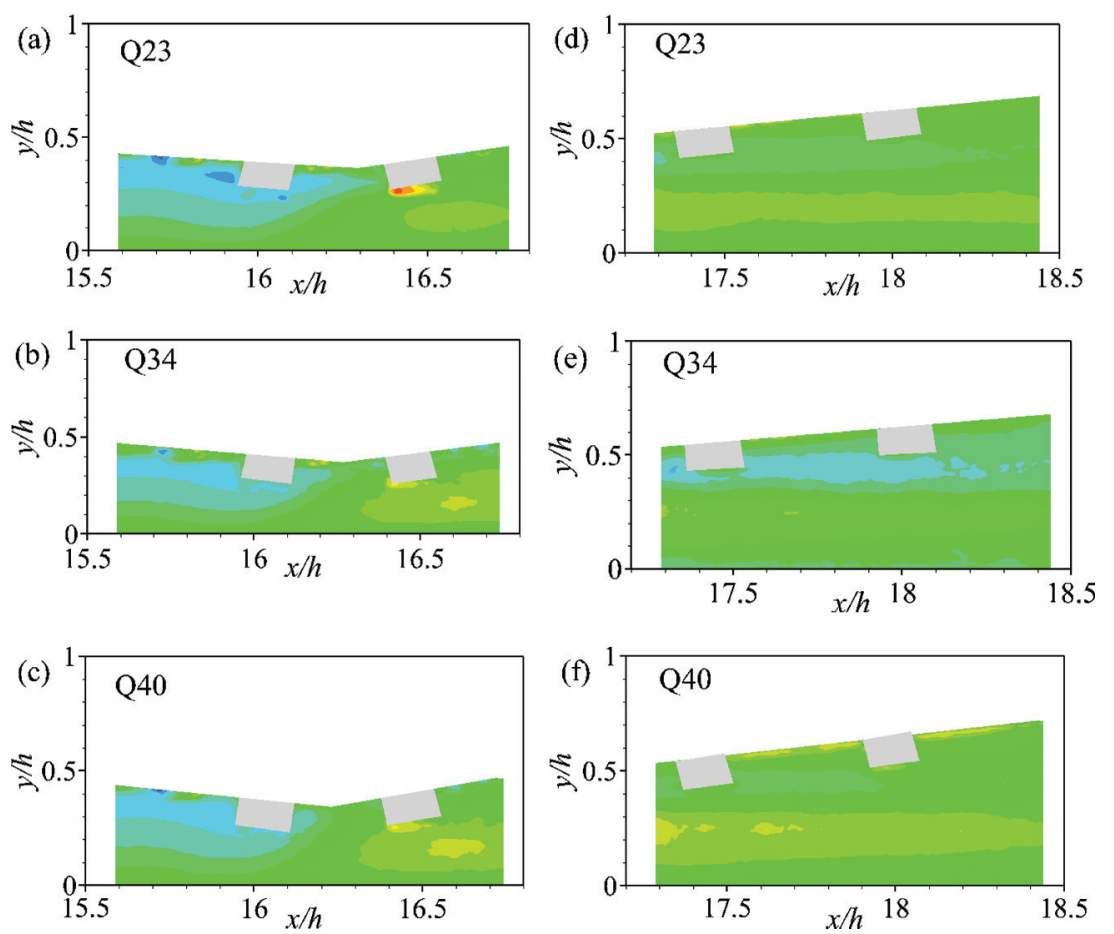

- Published by NRC Research Press 
Fig. 7. Profiles of $(a)$ streamwise mean velocity distribution beneath the simulated ice jam at selected locations, and (b) distribution of local maximum streamwise mean velocity wall-normal mean velocity. [Colour online.]
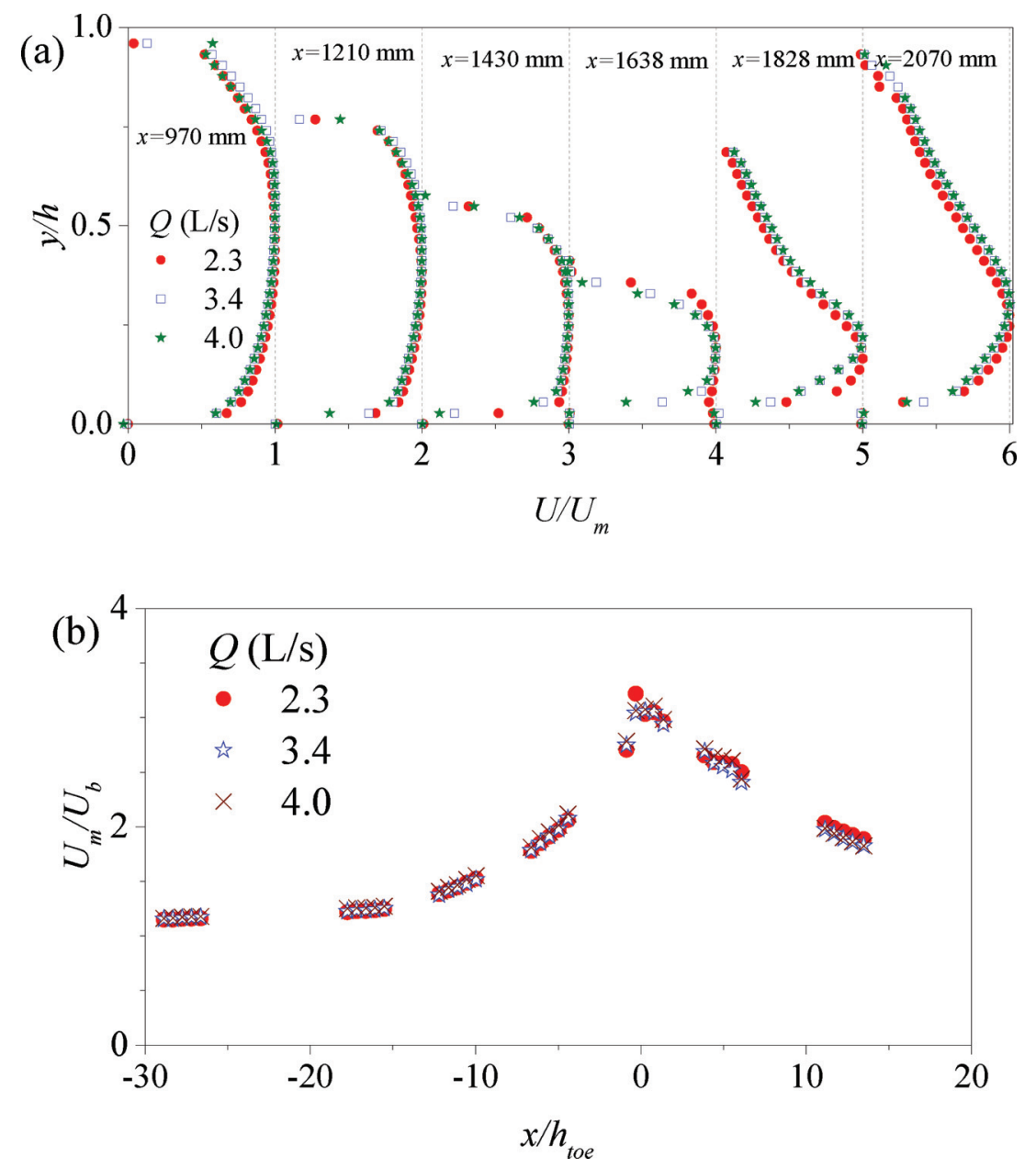

locations (Escudier et al. 1998). Within the lower toe section, the APG coupled with surface roughness increased the boundary layer thickness beneath the ice cover, thereby making the $U$ profile less uniform compared to those in the upper toe section. Thus, a wider shear zone (flow resistance) was established beneath the ice when the flow was subjected to an APG compared to the channel bottom. The level of velocity profile asymmetry increased with increasing flow discharge. Thus, subjecting the flow to APG caused $U_{\mathrm{m}}$ to shift farther away from the channel bottom by approximately $24 \%$, when the discharge was increased from Q23 to Q40. The streamwise mean velocity in the present investigation did not separate in the lower toe section when an APG was imposed on the flow. This is because the presence of ice roughness reduced the impact of APG on the flow as was indicated previously by Nyantekyi-Kwakye et al. (2018).

The distribution of normalized $U_{\mathrm{m}}$ with streamwise distance is shown in Fig. $7 b$. Within the equilibrium region, $U_{m}$ was unchanged with streamwise distance, since the flow was fully developed. However, within the upper toe section, a reduction in cross-sectional area meant the flow accelerated to ensure mass conservation. Values of $U_{\mathrm{m}}$ increased with streamwise distance within the upper toe section at a rate that was well-modeled using a second order polynomial. The peak $U_{\mathrm{m}}$ value occurred at the toe of the jam. For the different discharges, $U_{\mathrm{m}}$ increased by approximately $45 \%$ from the equilibrium section to the toe section. The very high flow variation within the upper toe section will greatly enhance sediment transport. The present results also indicate the high possibility of severe localized scouring at the toe section of the jam. Values of $U_{\mathrm{m}}$ decreased linearly with streamwise distance in the lower toe section due to APG imposed on the flow.

Figure 8 shows the distribution of normalized $V$ for the different discharges. The profile of $V$ in the equilibrium region $(x=$ $970 \mathrm{~mm}$ ) suggests suspension of sediments beneath the jam. Unlike the equilibrium region, the accelerating flow in the upper toe section produced predominantly negative $V$, which suggests an advection of secondary flow towards the bottom of the channel, and this is not significantly influenced by increasing the discharge. The advection towards the channel bottom also results in a suppressed boundary layer growth. The opposite is what happened in the lower toe section where the flow experienced APG. The decelerating flow produced positive $V$, which generates advection away from the channel bottom towards the ice cover. The positive $V$ field enhances the turbulent boundary layer growth beneath the jam and can lead to the rise of frazil ice towards the ice cover. From flow continuity, $\partial U / \partial x+\partial V / \partial y=0, \partial V / \partial y$ assumes negative and positive values at the inception of FPG and APG, respectively. Figure 8 supports the negative distribution of $\partial V / \partial y$ within the upper toe section except close to the jam where it becomes positive due to the no-slip boundary condition imposed on the flow by the presence of the jam. Similarly, $\partial V / \partial y$ assumed predominantly positive values within the lower toe section.

\section{Turbulent intensities}

Figure 9 depicts the distribution of the turbulent intensity profiles for the various flow discharges. Generally, FPG and APG modify the turbulence field by respectively decreasing and increasing 
Fig. 8. Wall-normal mean velocity beneath the simulated ice jam. [Colour online.]

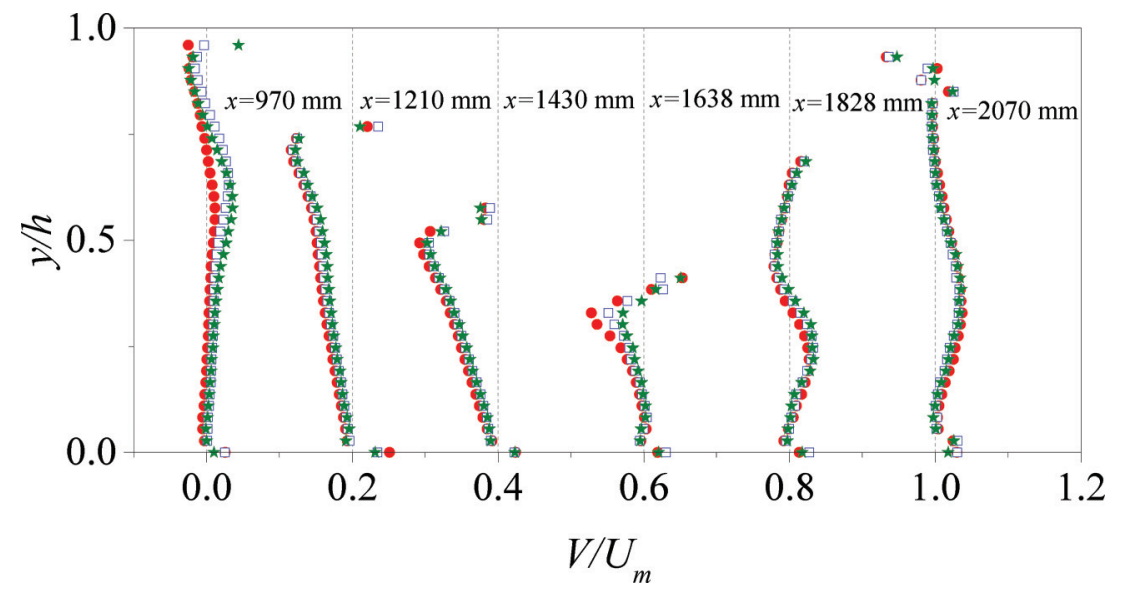

Fig. 9. Profiles of (a) streamwise, and (b) wall-normal turbulence intensities. [Colour online.]
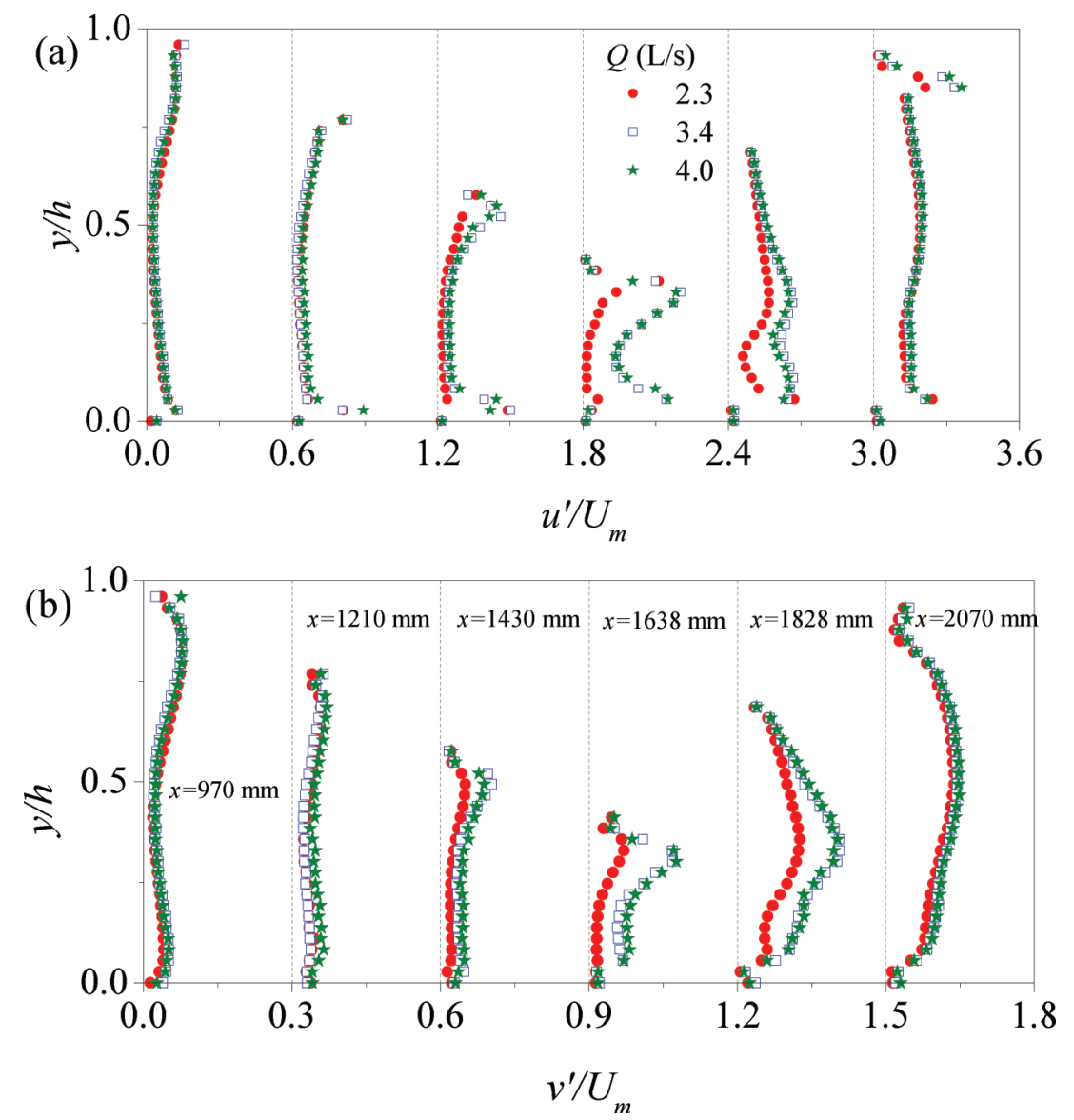

the turbulent intensities compared to zero-pressure gradient, which was experienced in the equilibrium region. Within the equilibrium region, the normalized streamwise turbulence intensity level was approximately 0.07 for all flow conditions, with no distinct near-wall peaks. At lower discharge, $Q 23$, the turbulence level remained unchanged (i.e., $u^{\prime} / U_{\mathrm{m}}=0.07$ ) within the upper toe section, with the peak occurring close to the jam. However, the turbulence level increased to 0.12 within the lower toe section when the flow was subjected to an APG, similar to reports by Monty et al. (2011), Nyantekyi-Kwakye et al. (2018), and Spalart and Watmuff (1993), who observed increased turbulence levels when a turbulent flow is subjected to an APG. The effect of discharge was observable within the toe region and lower toe sections. Close to the toe of the jam, normalized $u^{\prime}$ values increased by approximately 65\% when the discharge was increased from Q23 to Q34 and Q40. This observation strongly illustrates the flow approaching laminarization for Q23 compared to $Q 34$ and $Q 40$ at the toe section. Farther away from the toe, when the effect of APG dominated the flow, the percentage difference dropped to approximately 33\% (when the discharge changed from Q23 to Q34 and Q40), indicating high turbulence levels within the lower toe section. Similarly, for the wall-normal turbulence intensity, $v^{\prime}$, the effect of discharge was more pronounced when the flow was subjected to either FPG or APG. As expected, the levels of $v^{\prime}$ were 
Fig. 10. Profiles of (a) turbulent kinetic energy, and (b) Reynolds shear stress. [Colour online.]
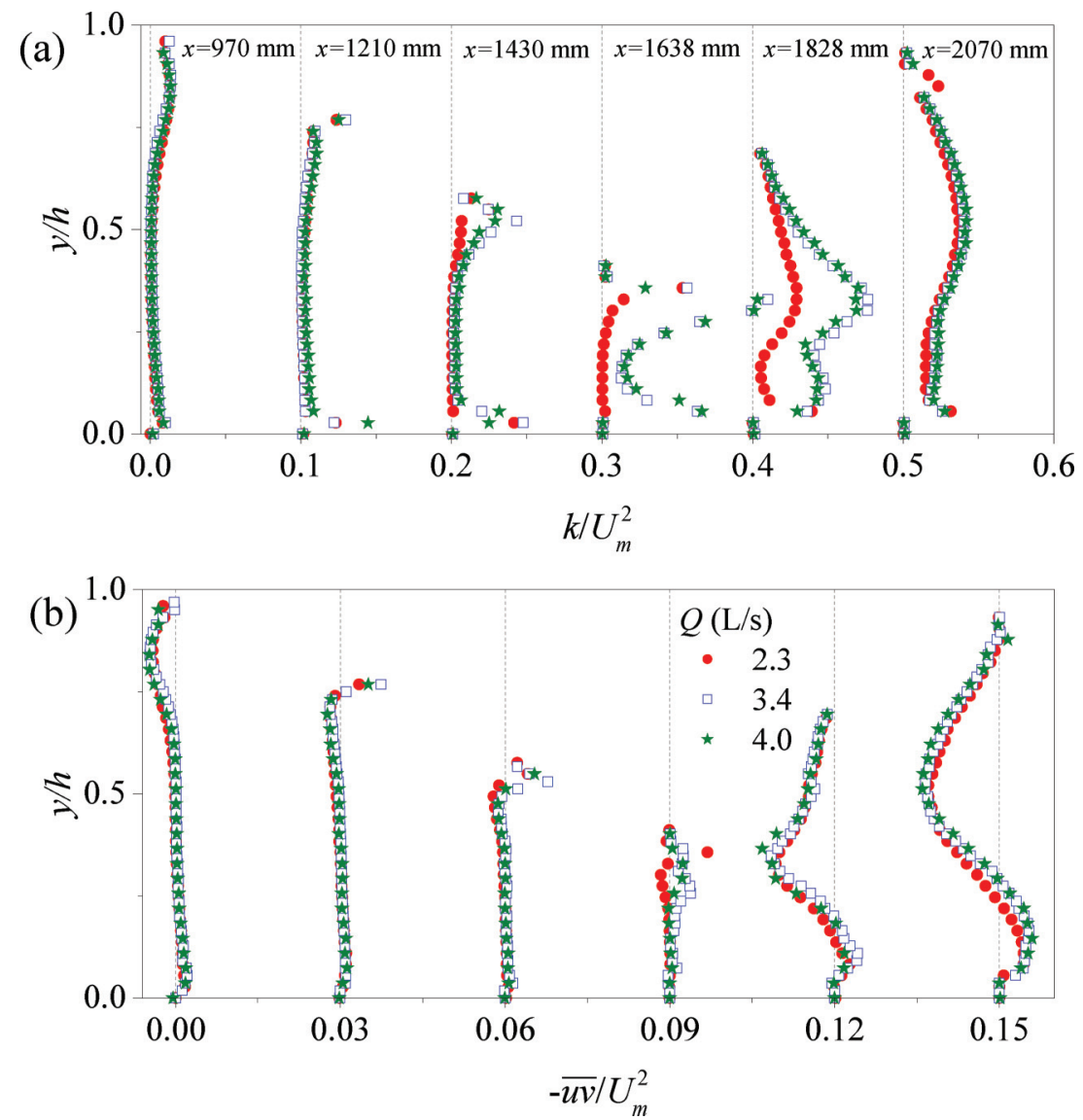

lower than the corresponding $u^{\prime}$ values at any given streamwise location, indicating large-scale anisotropy dominating the flow.

\section{Turbulent kinetic energy and Reynolds shear stress}

The turbulent kinetic energy, $k$, was estimated as $0.75\left(u^{\prime 2}+v^{\prime 2}\right)$, where $u^{\prime 2}$ and $v^{\prime 2}$ are the streamwise and wall-normal Reynolds normal stresses, respectively. Since no measurement was made in the spanwise direction, the spanwise Reynolds normal stress $\left(w^{\prime 2}\right)$ was approximated as $w^{\prime 2}=0.5\left(u^{\prime 2}+v^{\prime 2}\right)$. Figure $10 a$ shows the distribution of $k$ beneath the jam for the different discharges. There was no effect of discharge on $k$ within the equilibrium region. However, the subjection of the flow to both FPG and APG revealed the effect of pressure gradient on $k$. The first noticeable observation was an increase in the near-wall peaks of $k$ when the flow was subjected to pressure gradient. For instance, at Q23, $k$ increased considerably in the lower toe section when the flow was subjected to APG, which corroborates the report by Hosseini et al. (2016). The increase in $k$ in the lower toe section can be attributed to the excitation of energetic turbulent structures when subjected to APG. Increasing the discharge increased the production of turbulent kinetic energy within the toe and lower toe sections. The very low distribution of $k$ for $\mathrm{Q} 23$ at the toe of the jam compared to Q34 and Q40, suggests possible re-laminarization of the flow at low discharge, an observation that supports the lower turbulence levels for Q23 at the toe of the jam.

Figure $10 b$ shows the distribution of Reynolds shear stress, $-\overline{u v}$, beneath the simulated ice jam. There was no significant effect of discharge on $-\overline{u v}$ beneath the jam, although the presence of FPG produced positive $\partial U / \partial x$ and negative $\partial V / \partial y$. The latter has a greater tendency of flattening the large eddies in the flow, thereby reducing their contribution towards the production of $-\overline{u v}$. There was a dramatic increase in $-\overline{u v}$ when the flow was subjected to an
APG. Thus, the interplay of APG and surface roughness augments the production of $-\overline{u v}$ (Tsikata and Tachie 2013). Figure 11 illustrates the distribution of the wall-normal locations for $U_{\mathrm{m}}$ (denoted as $y_{\mathrm{m}}$ ) and $-\overline{u v}=0$ (denoted as $y_{\mathrm{uv}}$ ). Ideally, these two locations must coincide to enable eddy viscosity-based turbulence models to accurately predict such flow fields. From Fig. 11, these two locations did not coincide within the equilibrium region with $y_{\mathrm{uv}}$ occurring closer to the ice cover compared to $y_{\mathrm{m}}$ for all test cases. The location $y_{\mathrm{uv}}$ was predominantly closer to the channel bottom due to the asymmetric roughness distribution. This observation suggests that applying a standard eddy viscosity-basedtk;4 turbulence model to the present flow configuration would not accurately predict the flow dynamics and supports the findings of Tsikata and Tachie (2013).

\section{Comparison of various measurement techniques}

Velocities estimated from the two-point, three-point, and sixtenth depth measurement techniques have been compared to the measured values integrated from the mean velocity profiles. The profiles were extracted in the equilibrium region at $970 \mathrm{~mm}$ and in the intact ice cover section downstream of the jam at $2070 \mathrm{~mm}$, since the flow within these two sections was not subjected to pressure gradient. Figure 12 shows the superimposition of the estimated and measured average velocities on the mean velocity profiles for the various discharges. A coefficient of 0.92 was adopted, following the work of Teal et al. (1994), to correct the estimated velocity using the six-tenth depth. Within the equilibrium region, all the techniques overestimated the average velocity, $U_{\text {avg }}$, but the two-point technique yielded the most accurate results. Changing the discharge resulted in a wider deviation of the estimation from $U_{\text {avg. }}$. Similarly, within the downstream intact ice cover section, the two-point and three-point techniques slightly 
Fig. 11. Comparison of $y_{\mathrm{m}}$ and $y_{\mathrm{uv}}$ locations along the simulated ice jam. [Colour online.]
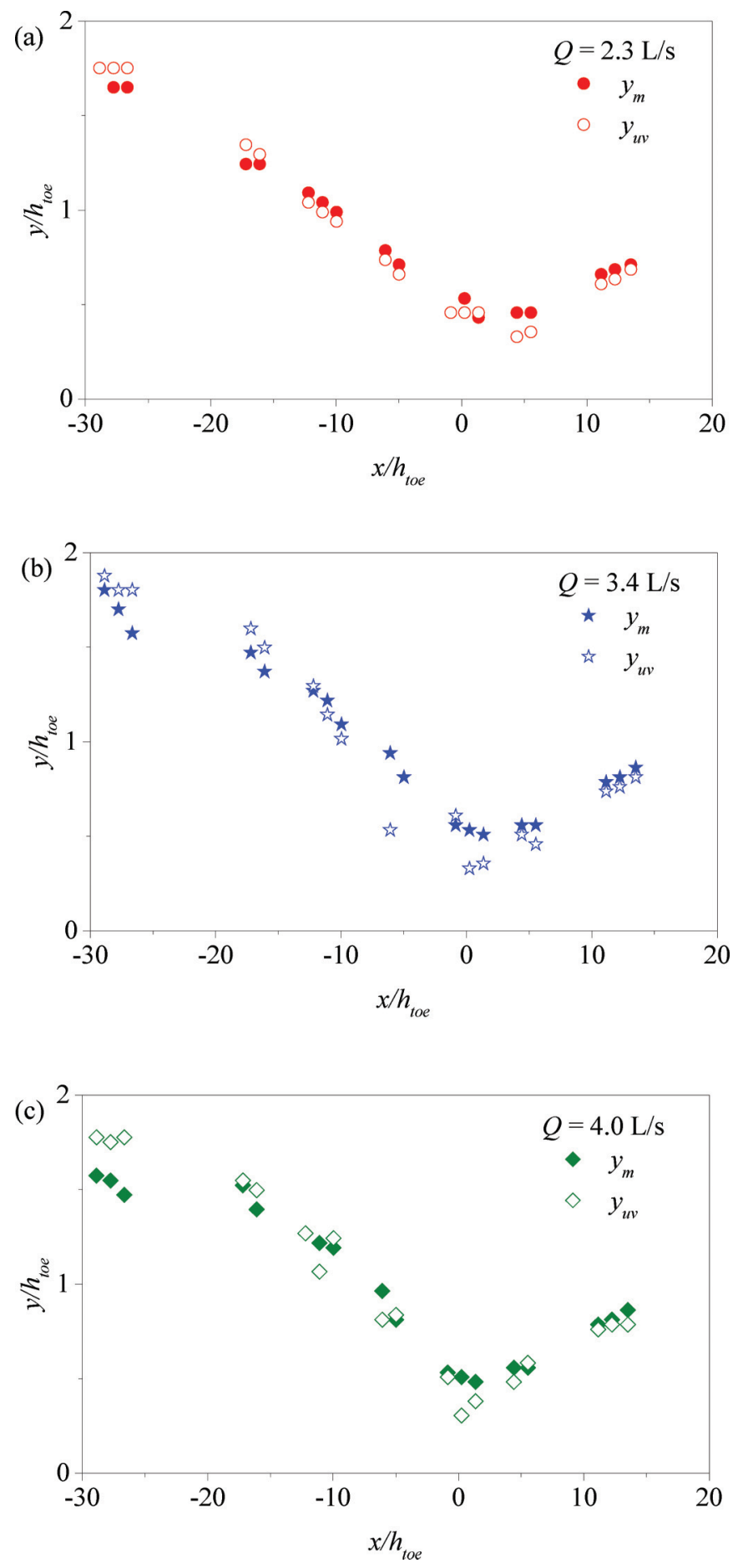

overestimated $U_{\text {avg. }}$. The six-tenth depth approach, however, consistently overestimated $U_{\text {avg }}$ within this section of the flow. The present observation indicates that thought should be given to the choice of coefficient needed to correct velocity measurements for the sixth-tenth approach under this type of ice cover. To attain accurate results from the six-tenth depth technique, the multiplicative coefficient should be adjusted at different sections of the flow. For instance, at $x=2070 \mathrm{~mm}$, a coefficient of 0.69 was appropriate to correct the six-tenth measurement after subjecting the flow to pressure gradient. Adjusting the coefficient accounts for the asymmetry of the velocity distribution due to pressure gradient and surface roughness. These coefficients may not be universal, but will be a function of the pressure gradient and (or) surface roughness.

The estimation error associated with the different measurement techniques was determined from eq. (3)

$$
\varepsilon=\left|\left(U_{\text {est }}-U_{\text {avg }}\right) / U_{\text {avg }}\right|
$$

In the above equation, $\varepsilon$ is the estimated error, and $U_{\text {est }}$ is the average velocity estimated using the outlined methods. It should be noted that the uncertainty in $U_{\text {avg }}$ was estimated to be $\pm 2.7 \%$. Values of $\varepsilon$ are indicated in Table 1 for the different discharges at $x=970 \mathrm{~mm}$ and $2070 \mathrm{~mm}$. For the different discharges $(Q 23, Q 34$, and Q40) the six-tenth depth yielded the largest $\varepsilon$ at $x=970 \mathrm{~mm}$, with $\varepsilon$ in the range of $4.7 \%-7.0 \%$, which is significant compared to the estimated uncertainties in the measurement. Similarly, an $\varepsilon$ in the range of $24.4 \%-44.3 \%$ was recorded for the six-tenth technique at $x=2070 \mathrm{~mm}$. The wider error range for the six-tenth depth is attributed to the choice of coefficient used to correct the average velocity, as pointed out in the previous section. Table 1 indicates a wider range of error downstream of the jam for the different measurement techniques. The present results also highlights the limitation of using these field techniques to estimate average velocities under high discharge (Teal et al. 1994). This can be partly attributed to the highly non-uniformity of the velocity profile downstream of the simulated jam, since higher velocity coupled with surface roughness results in higher flow resistance. As usual, the two-point technique yielded the least error range and can be easily adopted by engineers in the field. The average $\varepsilon$ obtained from the two-point technique was approximately $2.0 \%$ and $3.9 \%$ at $x=970 \mathrm{~mm}$ and $2070 \mathrm{~mm}$, respectively, which supports previous reports (Healy et al. 2002; Walker and Wang 1997; Teal et al. 1994).

\section{Assessment of two-parameter power law}

The velocity profiles obtained from eq. (1) are compared to measured profiles beneath the simulated jam and presented in Fig. 13. The profiles were extracted for the various discharges at streamwise locations corresponding to the equilibrium, upper toe, lower toe, and intact ice cover sections (downstream of the lower toe section of the simulated jam). Appropriate values of $m_{\mathrm{b}}$ and $m_{\mathrm{i}}$ were selected based on an iteration process. The values of $m_{\mathrm{b}}$ and $m_{\mathrm{i}}$ were influenced by the non-uniformity of roughness on the bed and simulated jam. Since the results for all three discharges are qualitatively similar, only the result for Q34 is shown in Fig. 13. There was good agreement between the measured velocity profiles and that predicted by the two-parameter power law in the equilibrium section of the simulated jam. As expected, the jam roughness provided a higher resistance to the flow compared to the bed roughness thereby yielding a larger value of $m_{\mathrm{b}}$ compared to $m_{\mathrm{i}}$ within the equilibrium section. Within the upper and lower toe sections of the jam, the power law could not replicate the measured velocity profiles close to the boundaries for any of the various discharges considered. This can be attributed to the subjection of the flow to favorable and adverse pressure gradients. The interplay of pressure gradients and surface roughness greatly influenced the values of both $m_{\mathrm{b}}$ and $m_{\mathrm{i}}$. The values of $m_{\mathrm{b}}$ and $m_{\mathrm{i}}$ were in the range of 0.3 to 5.0 , with predominantly lower values when the flow was subjected to pressure gradient compared to the equilibrium section. The lower limit of 0.3 in the present study is less than 1.5 reported by Teal et al. (1994) for flow beneath a uniform ice cover without pressure gradient. The values of $m_{i}$ were relatively smaller than $m_{\mathrm{b}}$ due to the effectiveness of the square acrylic cubes in resisting the flow compared to the sandpaper used at the channel bottom. Although $m_{\mathrm{b}}$ and $m_{\mathrm{i}}$ are dependent on boundary roughness, the present results indicate that these val- 
Fig. 12. Comparison of the different measurement techniques to the measured velocity in the equilibrium and intact ice-cover sections of the jam. [Colour online.]
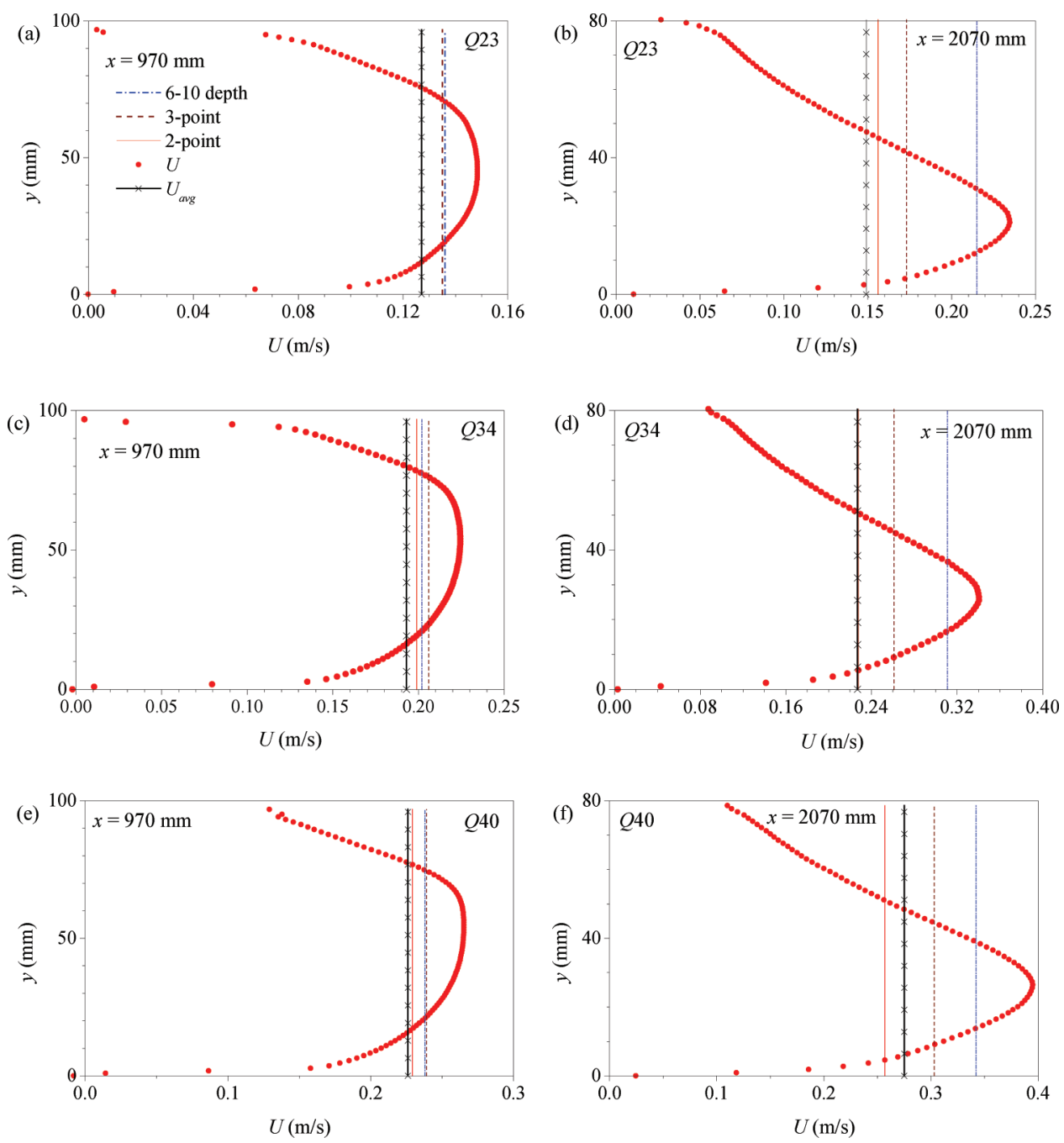

Table 1. Estimated error for the various measurement techniques.

\begin{tabular}{|c|c|c|c|c|c|c|}
\hline \multirow[b]{3}{*}{ Techniques } & \multicolumn{6}{|c|}{$\%$ error $(\varepsilon)$} \\
\hline & \multicolumn{2}{|l|}{ Q23 } & \multicolumn{2}{|l|}{ Q34 } & \multicolumn{2}{|l|}{ Q40 } \\
\hline & $x=970$ & $x=2070$ & $x=970$ & $x=2070$ & $x=970$ & $x=2070$ \\
\hline 2-point & 1.7 & 4.9 & 3.1 & 0.1 & 1.1 & 6.6 \\
\hline 3-point & 6.6 & 16.5 & 6.7 & 14.7 & 5.6 & 10.0 \\
\hline 6-10 depth & 7.0 & 44.3 & 4.7 & 36.7 & 5.4 & 24.4 \\
\hline
\end{tabular}

ues were also influenced by pressure gradient. Thus, the interplay of APG and surface roughness created more flow resistance in the lower toe section of the simulated jam. This resulted in lower values for both $m_{\mathrm{b}}$ and $m_{\mathrm{i}}$; which was in the range $0.3 \leq m_{\mathrm{b}, \mathrm{i}} \leq 1.2$.

\section{Conclusions}

A particle image velocimetry system was used to investigate upstream jam angle and discharge on the flow dynamics beneath a simulated rough ice jam. For the upstream jam angle, the discharge was maintained at $3.4 \mathrm{~L} / \mathrm{s}$, while the upstream jam angle was varied from $4^{\circ}$ to $6^{\circ}$. The discharge values investigated were $2.3,3.4$, and $4.0 \mathrm{~L} / \mathrm{s}$. The present investigation is the first to analyze the mean and turbulence fields beneath a simulated ice jam and to assess one-point statistics extracted at relevant sections

Fig. 13. Comparison of two-parameter power law velocity profiles with measured data. [Colour online.]

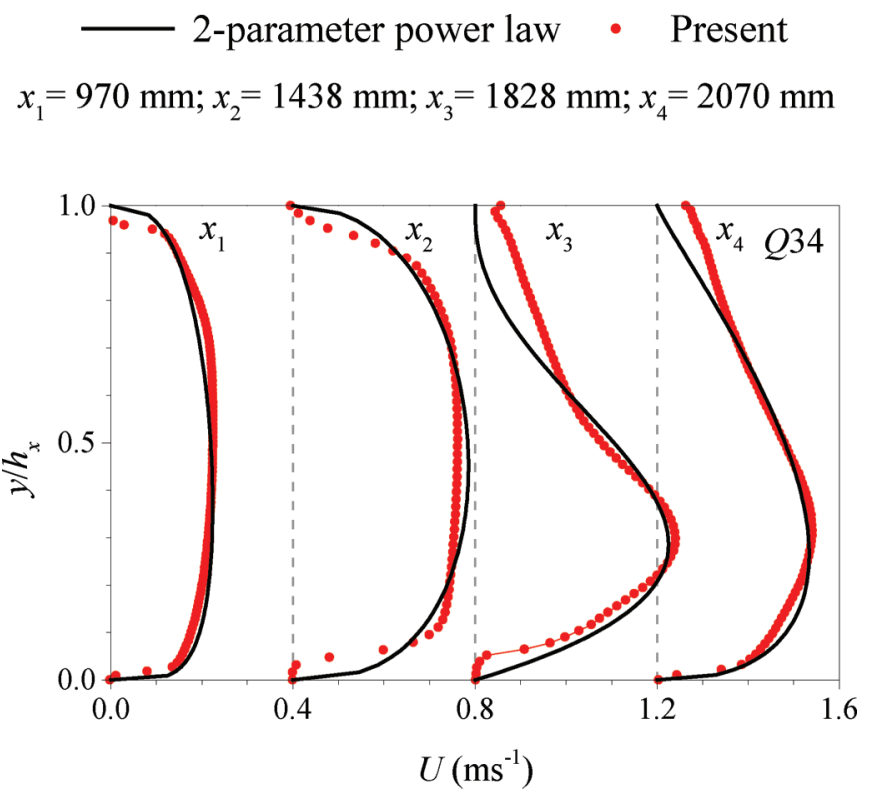

- Published by NRC Research Press 
beneath the ice jam. Generally, the flow accelerates in the presence of a FPG and changing the upstream angle did not have any significant impact on the acceleration parameter, $4.5 \times 10^{6}$ (obtained for the two upstream jam angles). The velocity contours showed that the mean flow accelerated and decelerated within the upper and lower toe sections due to FPG and APG, respectively. Increasing discharge values did not modify the streamwise mean velocity field using appropriate scales for normalization. The distribution of the wall-normal mean velocity suggests possible uplift of frazil ice towards the ice cover and suspension of bedload beneath the simulated jam. This occurrence was not significantly influenced by changing the discharge.

Increasing the discharge increased the turbulent intensities by approximately $65 \%$ and $33 \%$ within the upper and lower toe sections of the simulated jam, respectively. Similarly, changing the discharge increased the turbulent kinetic energy under APG. The increase in turbulent kinetic energy can be attributed to the excitation of energetic turbulent eddies in the presence of APG. The distribution of $k$ within the toe section of the jam suggests the tendency of the lower discharge approaching re-laminarization compared to the high discharges. Although there was no significant effect of discharge on the Reynolds shear stress levels, the FPG and APG in the upper and lower toe sections decreased and increased the shear stress levels, respectively.

From the typical velocity distribution beneath the simulated jam, average values of the streamwise velocities were compared to estimated values obtained using the two-point, three-point, and six-tenth depth techniques. The estimated error was used to determine the accuracy of these three measurement techniques. Almost all the measurement techniques yielded large errors at high discharges, highlighting the drawback of their predicting capabilities under high discharge conditions. However, the twopoint technique predominantly yielded lower estimation errors and thus remained suitable for estimating the average velocity under ice-covered flow in the field. The two-parameter power law was also assessed using the current experimental data. The twoparameter power law yielded acceptable results within the equilibrium section of the jam. However, the predicting accuracy of this technique diminished close to the boundaries when the flow was subjected to pressure gradient.

\section{Acknowledgements}

The authors are grateful to Manitoba Hydro and the Natural Sciences and Engineering Research Council of Canada for their financial support. We also thank Alexander Wall for his assistance in constructing the experimental setup.

\section{References}

Beltaos, S. 2001. Hydraulic roughness of breakup ice jams. Journal of Hydraulic Engineering, 127(8): 650-656. doi:10.1061/(ASCE)0733-9429(2001)127:8(650).

Escudier, M., Abdel-Hameed, A., Johnson, M., and Sutcliffe, C. 1998. Laminarisation and re-transition of a turbulent boundary layer subjected to favourable pressure gradient. Experiments in Fluids, 25(5-6): 491-502. doi:10.1007| s003480050255.

Healy, D., Hicks, F., and Loewen, M. 2002. Unsteady velocity profiles under a floating cover. In Ice in the Environment: Proceedings of the 16th IAHR International Symposium on Ice, Dunedin, New Zealand, pp. 2-6.

Hosseini, S.M., Vinuesa, R., Schlatter, P., Hanifi, A., and Henningson, D.S. 2016. Direct numerical simulation of the flow around a wing section at moderate Reynolds number. International Journal of Heat and Fluid Flow, 61: 117-128. doi:10.1016/j.ijheatfluidflow.2016.02.001.

Monty, J., Harun, Z., and Marusic, I. 2011. A parametric study of adverse pressure gradient turbulent boundary layers. International Journal of Heat and Fluid Flow, 32(3): 575-585. doi:10.1016/j.ijheatfluidflow.2011.03.004.

Nyantekyi-Kwakye, B., Pahlavan, H., Clark, S.P., Tachie, M.F., and Dow, K. 2018. Roughness effect on turbulent flow structure beneath a simulated ice jam. Journal of Hydraulic Research. doi:10.1080/00221686.2018.1473298.

Pahlavan, H., Clark, S.P., Wang, M., and Malenchak, J. 2015. An experimental investigation of turbulent flow characteristics beneath an ice jam. In CGU HS Committee on River Ice Processes and the Environment, 18th Workshop on the Hydraulics of Ice Covered Rivers, Quebec City, Quebec, Canada.

Pahlavan, H., Clark, S.P., Malenchak, J., and Wang, M. 2016. Effects of ice and bed roughness on turbulent flow characteristics beneath a simulated ice jam. In The 23rd IAHR International Symposium on Ice, Ann Arbor, Michigan USA, May 31 to June 3, 2016.

Spalart, P.R., and Watmuff, J.H. 1993. Experimental and numerical study of a turbulent boundary layer with pressure gradients. Journal of Fluid Mechanics, 249: 337-371. doi:10.1017/S002211209300120X.

Teal, M.J., Ettema, R., and Walker, J.F. 1994. Estimation of mean flow velocity in ice-covered channels. Journal of Hydraulic Engineering, 120(12): 1385-1400. doi:10.1061/(ASCE)0733-9429(1994)120:12(1385).

Tsikata, J., and Tachie, M. 2013. Adverse pressure gradient turbulent flows over rough walls. International Journal of Heat and Fluid Flow, 39: 127-145. doi: 10.1016/j.ijheatfluidflow.2012.11.001.

Walker, J.F., and Wang, D. 1997. Measurement of flow under ice covers in north America. Journal of Hydraulic Engineering, 123(11): 1037-1040. doi:10.1061/ (ASCE)0733-9429(1997)123:11(1037).

\section{List of symbols}

$h$ inlet channel height $(\mathrm{mm})$

$h_{\text {toe }}$ toe height $(\mathrm{mm})$

$K_{v}$ acceleration and deceleration parameter (-)

$K_{0}$ flow rate constant $(\mathrm{m} / \mathrm{s})$

$k$ turbulent kinetic energy $\left(\mathrm{m}^{2} / \mathrm{s}^{2}\right)$

$m_{\mathrm{b}}, m_{\mathrm{i}}$ parameters related to bed and ice cover (-)

$U$ streamwise mean velocity $(\mathrm{m} / \mathrm{s})$

$U_{\text {avg }}, U_{\text {est }}$ average and estimated velocities $(\mathrm{m} / \mathrm{s})$

$U_{\mathrm{b}}$ bulk velocity $(\mathrm{m} / \mathrm{s})$

$U_{\mathrm{m}}$ local streamwise maximum mean velocity $(\mathrm{m} / \mathrm{s})$

$u$ streamwise fluctuating velocity $(\mathrm{m} / \mathrm{s})$

$u^{\prime}$ streamwise turbulence intensity $(\mathrm{m} / \mathrm{s})$

$V$ wall-normal mean velocity $(\mathrm{m} / \mathrm{s})$

$v$ wall-normal fluctuating velocity $(\mathrm{m} / \mathrm{s})$

$v^{\prime}$ wall-normal turbulence intensity $(\mathrm{m} / \mathrm{s})$

$x$ streamwise distance $(\mathrm{mm})$

$y$ wall-normal distance $(\mathrm{mm})$

$y_{\mathrm{m}}$ wall-normal location of $U_{\mathrm{m}}(\mathrm{mm})$

$y_{\mathrm{uv}}$ wall-normal location of zero shear stress $(\mathrm{mm})$

$\alpha, \beta$ ice jam angles $\left(^{\circ}\right)$

$\varepsilon$ estimated percentage error (-)

$\nu$ kinematic viscosity $\left(\mathrm{m}^{2} / \mathrm{s}\right)$ 